\title{
A Calculation Model for Gas Transmission Efficiency of Long Distance Pipelines
}

\author{
Ying Xie, Mengmeng Cui and Zongming Yuan*
}

School of Petroleum and Natural Gas Engineering, Southwest Petroleum University, Chengdu 610500, PR China

\begin{abstract}
Due to the formation of corrosion products, natural gas liquids and gas hydrates in long distance pipelines, timely and effective pigging operations are necessary to improve the gas transmission efficiency, reduce pressure loss, as well as guarantee the safe operation of gas wells, pipelines and networks. Gas transmission efficiency is a parameter to reflect the working condition and cleanliness of pipelines, which is calculated by the division of actual gas transmission volume and theoretical gas transmission volume. In consideration of the characteristics of long distance gas pipelines, a calculation model of gas transmission efficiency is presented in this paper. A threshold value of $90 \%$ is used to measure the running state of pipelines, so as to determine whether a pigging operation should be conducted. The influence factors are analyzed. Suggestions on the operation strategy of long distance gas pipelines are stated.
\end{abstract}

Keywords: Gas transmission efficiency, long distance pipeline, model, pigging.

\section{INTRODUCTION}

As a result of energy consumption increase and environmental protection concerns, natural gas, an environmentally attractive fuel, plays an important role in the energy market [1]. Along with the continuous growth of fuel demand and the development of a large number of remote gas fields, the world long distance gas transmission pipelines have made a rapid improvement since the 1970s. The total length of the long distance gas pipelines in the world has been more than 1.5 million kilometers [2-4] at present. Although gas pipelines have obtained substantial progress [5] in design, construction, operation and management, material and the peak shaving technology of gas storages, how to improve the operation efficiency and effectiveness is still worth studying.

Gas transmission efficiency is a parameter to reflect the working condition and cleanliness of pipelines, which is calculated by the division of actual gas transmission volume and theoretical gas transmission volume. During the long term operation, dirt, corrosion products, natural gas hydrates and liquids gather together at the low-lying areas, leading to the decrease of gas transmission efficiency. Greater discharge pressure is required for compressors with a lower efficiency under the same condition, resulting in energy waste. Simultaneously, pipeline blockage will lead to fire, explosion, pollution or other ecocatastrophes. To prevent these types of events, gas transmission efficiency is adopted to measure the operation situation of natural gas pipelines for providing technical suggestions on whether pigging should be conducted.

*Address correspondence to this author at the School of Petroleum and Natural Gas Engineering, Southwest Petroleum University, 8\# Xindu Road, Xindu District, Chengdu City, Sichuan Province, Peoples Republic of China; Tel: 86-28-83033348; Fax: 86-28-83033248;

E-mail: zmyuan028@163.com
In consideration of the characteristics of long distance gas pipelines with multiple users and large changes of tube deposit, a calculation model of gas transmission efficiency is presented in this paper to measure the pipeline running state. When it is lower than $90 \%$, it is necessary to the implementation of pipeline pigging. Based on this model, the impacts of feed gas components and pipeline roughness on transmission efficiency are analyzed. The corresponding measures to improve it are put forward.

\section{CHARACTERISTICS OF LONG DISTANCE NATURAL GAS PIPELINES}

The long distance natural gas pipeline system [6] is the pipelines connected gas fields, oil associated gas or liquefied natural gas terminals with city gas stations. As a closed hydraulic system, it consists of stations and pipelines with the following characteristics [7].

(1) Since the gas consumption of users varies at different time of a day and different seasons of a year, the pipeline system has been in an unsteady state for a long time with stable gas supply. When the gas consumption is in a low peak position, gas is stored. When the gas consumption is in a high peak position, gas is discharged. That is to say, it is a system with peak shaving ability [8].

(2) To deliver gas from wells located in swamps, deserts and sea areas, pipelines are usually long in distance.

(3) High pressure and large diameter bring throughput increase and cost decrease. In consideration of economic factors and user requirements, the current long distance pipeline are large in diameter.

(4) With the development of electronic computer, instrument automation and information technology, the supervisory control and data acquisition system is 
used for pipeline automatic monitoring. However, flowmeters are usually set on gas supply and users. The actual flow rate of pipelines cannot be acquired directly. Since the long distance pipeline are large in diameter and long in distance, the peak shaving ability is huge. The tube deposit affects the actual flow rate of pipelines.

\section{METHODS FOR CALCULATING THE GAS TRANSMISSION EFFICIENCY}

The gas transmission efficiency coefficient $E$ is an important parameter reflecting the working condition and cleanliness of pipelines, which is calculated by

$E=\frac{Q_{r}}{Q}$

where $E$ is the gas transmission efficiency coefficient, nondimensional number; $Q_{r}$ is the actual gas transmission volume, $\mathrm{m}^{3} / \mathrm{s} ; Q$ is the theoretical gas transmission volume, $\mathrm{m}^{3} / \mathrm{s}$.

\subsection{Calculation of the Actual Gas Transmission Volume}

Fig. (1) shows a long distance natural gas pipeline system with a supply and $\mathrm{n}$ stations, where $Q_{\text {feed }}$ is the feed gas supply, $\operatorname{sta}(i)$ is on behalf of the $i^{\text {th }}$ gas station, and $q(i)$ is the gas delivery at the $i^{\text {th }}$ gas station.

Since the system is in a dynamic state, change of pressure and temperature will affect the tube storage. $Q_{\text {feed }}$ and $q(i)$ can be acquired by monitoring data. The actual flow rate between adjacent stations can be calculated by

$Q_{1-2}=Q_{\text {feed }}-q_{1}$

$Q_{2-3}=Q_{\text {feed }}-\frac{\Delta V_{1-2}}{t}-\left(q_{1}+q_{2}\right)$

$Q_{3-4}=Q_{\text {feed }}-\frac{\Delta V_{1-2}+\Delta V_{2-3}}{t}-\left(q_{1}+q_{2}+q_{3}\right)$

$Q_{\mathrm{i}-\mathrm{i}+1)}=Q_{\text {feed }}-\frac{\sum_{j=2}^{i} \Delta V_{(j-1)-j}}{t}-\sum_{j=1}^{i} q_{j}$

where the subscript $i$ is the $i^{\text {th }}$ gas station, $\frac{\Delta V_{(j-1)-j}}{t}$ represents the impact of the tube deposit between the $(j-1)^{\text {th }}$ station and the $j^{\text {th }}$ station on the actual gas transmission volume, $\mathrm{m}^{3} / \mathrm{s}$.
The natural gas consumption of users shows inhomogeneity in time, resulting in the change of the gas storage in a pipeline. For a pipe section between stations with an initial pressure of $P_{\mathrm{Q}}$ and a terminal pressure of $P_{\mathrm{Z}}$, the average pressure $P_{\mathrm{CP}}$ is

$P_{\mathrm{CP}}=\frac{2}{3}\left(P_{\mathrm{Q}}+\frac{P_{\mathrm{Z}}^{2}}{P_{\mathrm{Q}}+P_{\mathrm{Z}}}\right)$ by

The gas stored in this pipe section $V_{\mathrm{S}}$ can be calculated

$V_{\mathrm{S}}=V_{\mathrm{T}} \frac{P_{\mathrm{CP}}}{P_{0}} \frac{T_{0}}{T_{\mathrm{CP}} Z}$

where $V_{\mathrm{T}}$ is the geometric volume of the pipeline, $\mathrm{m}^{3} ; P_{0}$ is the standard pressure, $1.01325 \times 10^{5} \mathrm{~Pa}$;

$T_{0}$ is the standard temperature, $273.15 \mathrm{~K} ; T_{\mathrm{CP}}$ is the average temperature, which is set to the terminal temperature of the pipeline for approximate calculation, $\mathrm{K} ; Z$ is the compression coefficient under the average pressure and temperature.

\subsection{Calculation of the Theoretical Gas Transmission Volume}

For a pipeline with the same scope (Fig. 2), the one dimensional continuity equation [9] for gas flow is

$\frac{d P}{d x}+\rho v \frac{d v}{d x}=-g \rho \sin \theta-\frac{\lambda}{D} \frac{v^{2}}{2} \rho$

where $x$ is along the direction of length, $\mathrm{m} ; \rho$ is the gas density, $\mathrm{kg} / \mathrm{m}^{3} ; \quad v$ is the gas velocity, $\mathrm{m} / \mathrm{s} ; g$ is the gravitational acceleration, $\mathrm{m} / \mathrm{s}^{2} ; \theta$ is the angle between the pipe and the horizontal plane, rad; $\lambda$ is the friction factor; $D$ is the inner diameter, $\mathrm{m}$.

The theoretical gas transmission volume can be calculated by Equation 9 [7] for a pipeline with different scopes and large relief (Fig. 3).

$Q=C\left\{\frac{\left[P_{Q}^{2}-P_{Z}^{2}(1+a \Delta S)\right] D^{5}}{\lambda Z d T_{C P} L\left[1+\frac{a}{2 L} \sum\left(S_{i}+S_{i-1}\right) L_{i}\right]}\right\}^{0.5}$

where $Q$ is the theoretical gas transmission volume under the standard condition, $\mathrm{m}^{3} / \mathrm{s} ; \mathrm{C}$ is a constant, $0.0384 \mathrm{~m}^{2} \cdot \mathrm{s} \cdot \sqrt{K}$ $/ \mathrm{kg} ; \Delta S$ is the elevation difference of the start and end of the pipeline, $\mathrm{m} ; d$ is the relative density; $L$ is the pipeline length, m. $a=\frac{2 g}{Z R T}$.

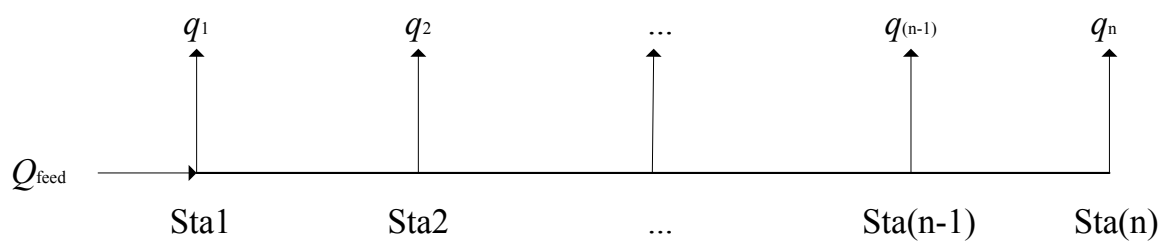

Fig. (1). A thumbnail photo of a long distance natural gas pipeline system with $\mathrm{n}$ stations. 


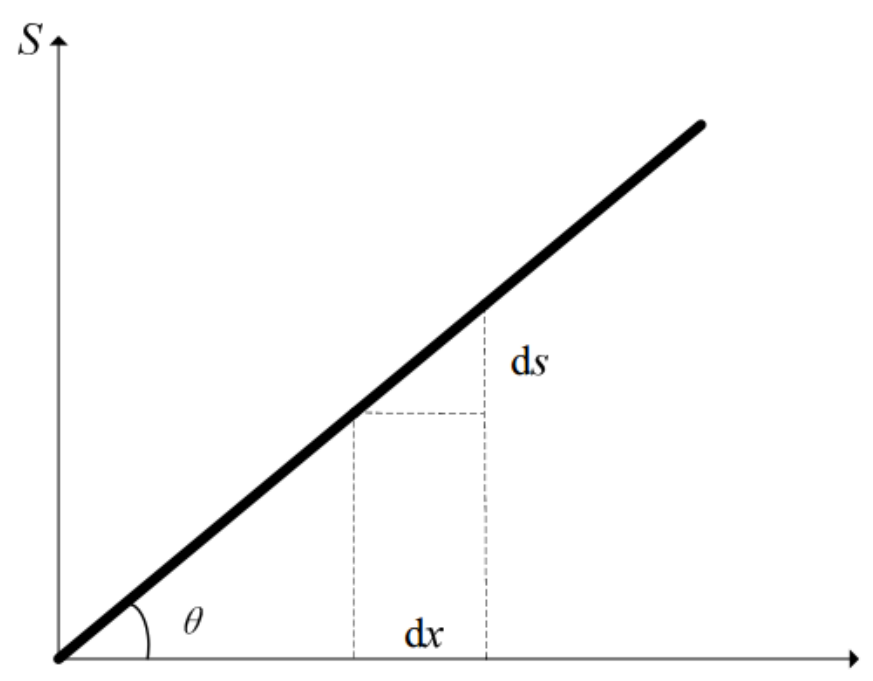

$L$

Fig. (2). A gas transmission pipeline with the same scope ( $S$ is the elevation, $L$ is the length).

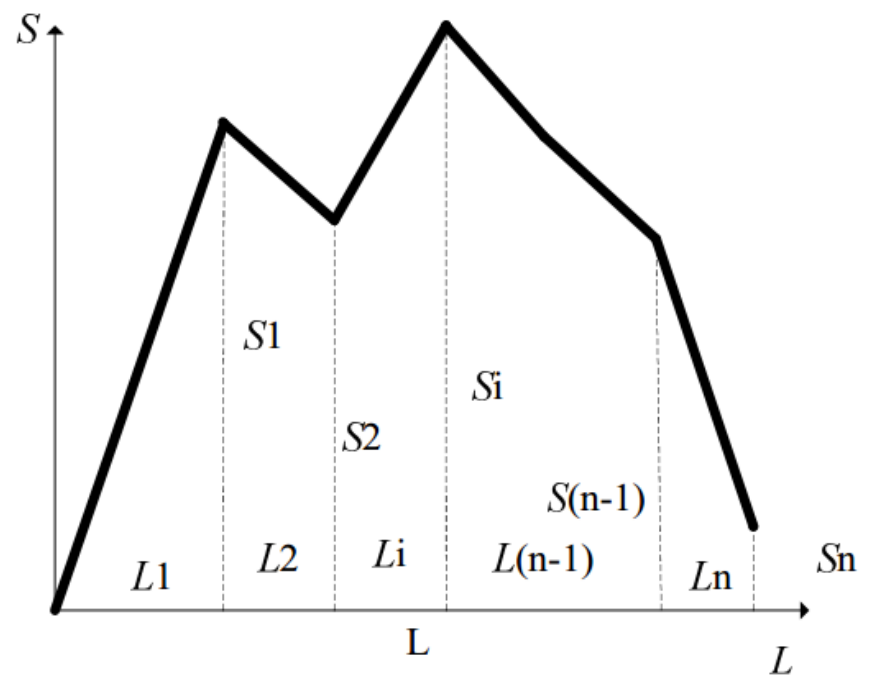

Fig. (3). A gas transmission pipeline with large relief.

Since the gas flow state of long distance pipelines is always in the region of quadratic resistance law, ColebrookWhite equation [10] is adopted for the calculation of friction factor, which is given by

$\sqrt{\frac{1}{\lambda}}=-2 \log \left(\frac{\varepsilon}{3.7065 D}+\frac{2.5226}{\operatorname{Re} \sqrt{\lambda}}\right)$

where $\varepsilon$ is the roughness, $\mathrm{m}$; Re is the Reynolds number.

The gas transmission efficiency can be obtained by the integration of the actual gas transmission volume and the theoretical gas transmission volume. A threshold value of $90 \%$ is used to measure the pipeline running state, so as to determine whether a pigging operation should be conducted. Combined with the former study $[11,12]$, the relationship between the pressure drop and efficiency under a certain throughout can be applied in engineering practice for pigging cycle determination.

\section{ANALYSIS OF THE INFLUENCE FACTORS}

Gas transmission efficiency is a parameter to measure the pipeline transmission capacity. Several factors have an impact on it such as feed gas components and wall roughness.

The impurities have a great influence on the working condition, economic benefit and service life of gas pipelines, including the mechanical impurities and corrosion products, such as dust, iron sulfide powder and free water, hydrocarbon condensate, hydrogen sulfide and carbon dioxide. Liquid hydrocarbons may cause pipeline blockage and reduce the transmission efficiency, so it is the same with free water. Natural gas hydrate can also be harmful for pipeline.

In intuitive view, the compression factor decreases with the increase of impurities in feeding gas, indicating the deviation degree of gas from the ideal state. Under the same condition, higher initial pressure is needed with a lower compression factor, which means the gas transmission efficiency decreases with the increase of impurities in feed gas.

The hydraulic frictional resistance coefficient is a function of the absolute roughness. The resistance coefficient increases with the increase of roughness, leading to a lower gas transmission capacity. Fig. (4) depicts the relationships between pressure loss and roughness under different throughout. It is concluded that the transmission efficiency decreases with the increase of roughness.

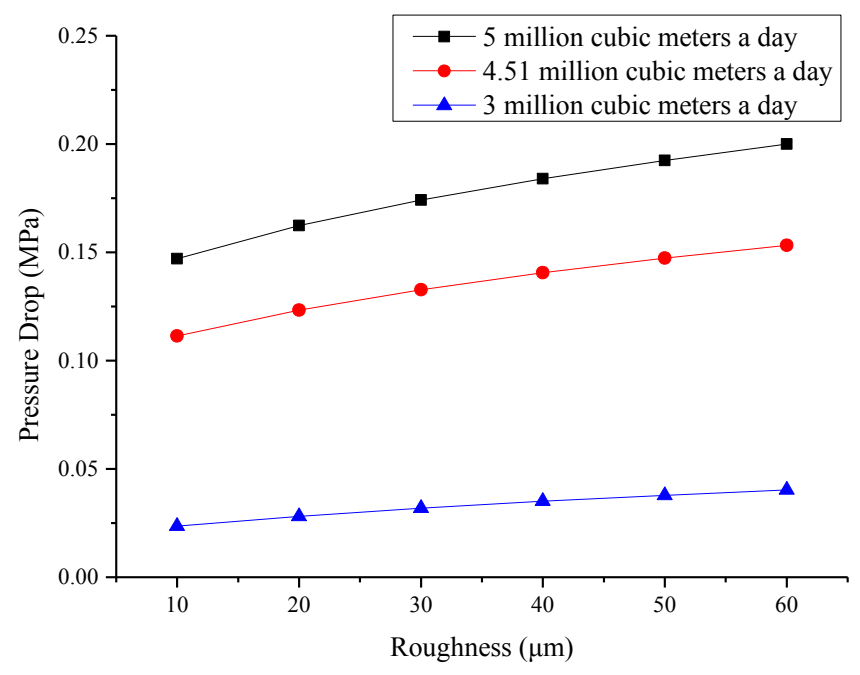

Fig. (4). Relationships between pressure loss and roughness under different throughout.

\section{IMPROVEMENTS OF THE GAS TRANSMISSION EFFICIENCY}

Through the analysis of the influence factor, the corresponding measures to improve it are put forward. Effective pretreatment of impurities in feeding gas prevents the heavy hydrocarbons and free water for blocking the pipeline, thereby increasing the transmission efficiency. 
Reasonable pigging is conducive for the removal of mechanical impurities and corrosion products, so as to reduce the energy waste. Drag reducer $[13,14]$ has been proven to be good for improving the gas flow characteristics, extending the pigging period, reducing the transportation cost, and increasing the throughout. The local pressure loss can be reduced by reasonable selection of gas purifying equipment, such as dust removers and filters. The ball valve is better than the gate valve with a smaller pressure loss. On the premise of requirements satisfaction, detection equipment inside the pipe should be less used.

\section{CONCLUSION}

This paper presents a calculation model of gas transmission efficiency for long distance pipelines with multiple users and large changes of tube deposit. The calculation methods of the actual and theoretical gas transmission volume are stated. Based on this model, the impacts of feeding gas components and pipeline roughness on transmission efficiency are analyzed. The gas transmission efficiency decreases with the increase of impurities in feeding gas and the increase of roughness. Thus, the corresponding measures to improve it are put forward as effective pretreatment, reasonable pigging, injection of drag reducer. Other measures to reduce local pressure loss are illustrated, simultaneously.

\section{CONFLICT OF INTEREST}

The authors confirm that this article content has no conflict of interest.

\section{ACKNOWLEDGEMENTS}

This work is supported by oil and gas storage and transportation engineering department in Southwest Petroleum University, China.

\section{REFERENCES}

[1] U.S. Energy information administration. international energy outlook 2013. http://www.eia.gov/forecasts/ieo/. (Accessed Jan 1, 2015).

[2] Yan, G. Summarization of long-distance gas transmission pipeline in the world. Nat. Oil Gas J., 2000, 18(3), 9-19.

[3] Zhang, S. Construction of gas transmission pipeline abroad. Nat Oil Gas J., 2000, 18(4), 1-10.

[4] Tian, Y.; Shan, L.; Sun, C.; Wei, K. Development course and status of foreign natural gas pipelines and its light shed on China. Petro Plann. Eng., 2010, 21(5), 1-6.

[5] Song, A.; Liang, G.; Wang, W. Status Quo and development of worldwide oil and gas pipelines. Oil Gas Stor. Trans., 2006, 25(10), 1-6.

[6] Mohitpour, M.; Golshan, H.; Murray, A. Natl Gas Transm. ASME Press, 2007.

[7] Li, C. Pipeline Transmission of Natural Gas. Petroleum Industry Press: Beijing, 2008.

[8] Shang, L.; Pan, Z.; Li, Q.; Zhou, Y. Study on the gas storage and peak shaving with end-section of gas transmission trunkline. Oil Gas Stor. Trans., 2008, 27(7), 27-30.

[9] Tian, S.; Adewumi, M. Development of analytical design equation for gas pipelines. SPE Prod. Facil., 1994, 9(02), 100-106.

[10] Colebrook, C. Turbulent Flow in Pipes, with particular reference to the Transition Region between the Smooth and Rough Pipe Laws. $J$. Inst. Civil Eng., 1939, 11(4), 133-156.

[11] Xie, Y.; Cui, M.; Quan, K.; Yuan, Z.; He, S. Pigging cycle for Yulin-Jinan Gas Pipeline. Oil Gas Stor. Trans., 2014, 33(5), 522525.

[12] Zhao, J.; Yang, L.; Wei, M.; Li, T.; Shen, L. Determination of pigging cycle for gas transmission pipeline in Sulige gasfield. Oil Gas Stor. Trans., 2011, 30(1), 71-72.

[13] Naess, R. Pressure loss in gas pipe with adsorbed layers. Department of Petroleum Engineering and Applied Geophysics of NTNU, 1999.

[14] Olivares-Xometl, O.; Likhanova, N.; Dominguez-Aguilar, M.; Hallen, J.; Zamudio, L.; Arce, E. Surface analysis of inhibitor films formed by imidazolines and amides on mild steel in an acidic environment. Appl. Surf. Sci., 2006, 252(6), 2139-2152.

(C) Xie et al.; Licensee Bentham Open.

This is an open access article licensed under the terms of the Creative Commons Attribution Non-Commercial License (http://creativecommons.org/licenses/ by-nc/4.0/) which permits unrestricted, non-commercial use, distribution and reproduction in any medium, provided the work is properly cited. 